TAO, Vol. 17, No. 1, 295-316, March 2006

\title{
Estimating Seasonal Basin Rainfall Using Tabu Search
}

\author{
Ming-Hsu Li ${ }^{1, *}$, Ching-Pin Tung ${ }^{2}$, Chung-Hsiung Sui ${ }^{1}$, and Fu-Hsiung Yang ${ }^{3}$
}

(Manuscript received 14 July 2005, in final form 1 November 2005)

\begin{abstract}
Basin areal rainfall is often estimated utilizing gauge data observed at specific locations adjusted on the basis of prescribed weighting factors for each station. The resultant data have many hydrological and meteorological applications. Several hydrometeorological factors, such as spatial rainfall variability, orographic effects, and synoptic frontal systems can greatly affect gauge-catch efficiency in watersheds that lack sufficient gauge densities. As a result, gauge weightings that are determined by conventional approaches (e.g., arithmetic averages, and the Thiessen polygon) that lack consideration for watershed and rainfall characteristics may introduce unexpected errors in estimated basin rainfall. Our approach is to combine hydrological routings and Tabu search using errors of estimated stream discharges as the objective function to determine gauge-weighting factors. Through hydrological routings, basin and rainfall characteristics are implicitly considered into the estimation of discharges representing an integrated basin response to rainfall forcing. The Lanyang River Basin located in northeastern Taiwan is the domain of interest, where wet- and dryseason rainfalls are mainly attributed to typhoons and the winter monsoon, respectively. Wet-season results show significant orographic effect on gauge weightings due to the large cyclonic circulation interacting with the mountainous topography. Dry-season results further demonstrate the importance of orographic effect, especially at one particular station located on the windward side of the mountains with respect to the persistent frontal system of the winter monsoon.
\end{abstract}

(Key words: Rainfall, Gauge weighting factors, Hydrological routing, Tabu search)

\footnotetext{
${ }^{1}$ Institute of Hydrological Sciences, National Central University, Chung-Li, Taiwan, ROC

2 Department of Bioenvironmental Systems Engineering, National Taiwan University, Taipei, Taiwan, ROC

${ }^{3}$ Episil Technologies Inc., Hsin-Chu, Taiwan, ROC

* Corresponding author address. Prof. Ming-Hsu Li, Institute of Hydrological Sciences, National Central University, Chung-Li, Taiwan, ROC; E-mail: mli@cc.ncu.edu.tw
} 


\section{INTRODUCTION}

Estimation of precipitation over a basin from gauge stations is important in many hydrological applications, such as rainfall-runoff analysis and water resources management. Rainfall observed at randomly located stations can only provide point measurements and requires spatial interpolation techniques for upscaling to a basin domain. As documented in many hydrology textbooks (McCuen 1998; Dingman 2002; Viessman and Lewis 2003), several simple approaches, for example the arithmetic average, the Thiessen polygon (1911), and the isohystal method, can be applied to estimate basin average rainfall. Although the implementations of these approaches are straightforward and easy, the basin rainfall amount might be overestimated or underestimated due to high spatial variability of rainfalls and insufficient gauge densities and distributions in most watersheds. When regional rainfall patterns in a mountainous watershed are strongly influenced by topography, simple approaches, without taking orographic effect into consideration, are not suitable for estimating basin rainfall (Dingman 2002).

Yoo and Ha (2002) found that the sampling errors in the estimation of basin average rainfall from randomly located rain gauges are more or less the same as the standard deviation of the arithmetic average. The sampling errors of evenly spaced gauge networks may significantly decrease when some threshold number of gauges (i.e., more gauges) are involved for estimation. However, gauge densities in most basins are practically impossible to meet this criterion.

In recent research, optimal interpolation approaches using geostatistical methods (e.g., varieties of kriging) that take into account the spatial correlation of gauge observations to predict rainfall at unsampled locations and into areal estimations are increasing preferred (Tabios and Salas 1985; Bacchi and Kottegoda 1995; Pardo-Igúzquiza 1998). With secondary information from the digital elevation model, Goovaerts (2000) applied three krging approaches to incorporate gridded elevation data into the spatial interpolation of rainfall with monthly and annual point observations. The results showed larger prediction errors from the two compared conventional univariate estimations, inverse square distance and the Thiessen polygon; these are attributed to the ignorance of orographic effect and rainfall spatial correlation. However, the relationship between basin rainfall patterns and regional rainfall climatology might be embedded through these multivariate geostatistical algorithms although they are not clearly revealed and discussed.

For the estimation of seasonal and annual basin rainfall, the low frequency of persistent regional climatology, rather than the high frequency of variable extreme events may play a relatively important role. Einfalt et al. (1998) used the synoptic classifications of general weather type to examine the spatial validity of point rainfall measurements with the areal rainfall estimated by the Thiessen procedure and found certain reductions should be applied to individual gauge data for long-term implementations.

In view of basin rainfall-runoff analysis, stream discharge represents an integrated basin response to rainfall forcing. Watershed characteristics, such as landuse practices and river geomorphology, might greatly affect stream discharges in addition to the rainfall spatial variability. Singh (1997) analyzed the effect of spatial and temporal variability in rainfall and watershed characteristics on stream flow hydrographs and found the timing and peaks of 
hydrographs are mainly attributed to the spatial variability of rainfall and temporally variable rainfall, respectively. Chaubey et al. (1999) concluded the large uncertainty in estimated hydrological model parameters could be induced without considering spatial rainfall variability of the grid-based rainfalls captured by the Thiessen method. Syed et al. (2003) assessed the spatial geometric properties of storms in explaining the observed basin runoffs.

The essential concept of this study is that weighting factors for each gauge station used in estimating seasonal basin rainfall should be determined to reflect basin rainfall characteristics, specifically rainfall climatology, rather than the weighting factors given by conventional adhoc approaches. Our approach is to treat each gauge weighting as an unknown parameter to be resolved by incorporating physically based hydrological routing and the tabu search. Observed stream discharges could be applied as a good indicator for examining spatial rainfall characteristics since they represent the most straightforward basin response to rainfall forcing.

The term of Tabu search (TS) was first introduced by Glover (1986). The advantage of TS is that it allows movement toward temporarily worse solutions which one might encounter on the path toward a global optimal solution, to escape being trapped by local optimum. It has been demonstrated as a powerful algorithm for identifying the highly nonlinear parameter structure of many hydrological applications (Zheng and Wang 1996, 1999; Tung and Chou 2002).

The Lanyan River Basin located in northeastern Taiwan (Fig. 1) was used to demonstrate our approach. A total of six rainfall gauge stations and one stream stage station near the basin outlet provide observed rainfalls and stream discharges, interpreted by a calibrated stage-discharge rating curve, at daily resolutions. In our approach, the errors between estimated and observed stream flows are the objective function with wet season, dry season, and annual rainfall gauge weighting factors being determined for estimating basin rainfall.

\section{RAINFALL CLIMATOLOGY OF STUDY AREA}

The study area is the Lanyan River Basin, located in northeastern Taiwan, with a drainage area of about $978 \mathrm{~km}^{2}$ within which $67 \%$ is mountainous terrain (Fig. 1). The main channel originates at an altitude of $3535 \mathrm{~m}$ and runs a total length of $73 \mathrm{~km}$. Without any disturbance from manmade structures, such as reservoirs and dams, the stream flow of the Lanyan River intrinsically reflects watershed response to rainfall characteristics. To understand the rainfall climatology of the Lanyan River Basin, it is necessary to introduce the spatial and temporal rainfall pattern of this oceanic island in advance.

The overall rainfall pattern in Taiwan is strongly affected by the East Asian monsoons and associated interactions with the presence of the north-south-orientated Central Mountain Range resulting in the orographic effect. The northeasterly monsoon brings in precipitation over the windward northeastern and eastern coastal areas during the dry season (typically from November to April of the following year). For the wet season (May to October), precipitation is partially attributed to the southwesterly monsoon over the western windward southwestern and western coastal areas, and mainly to the typhoons or tropical cyclones originating in the West Pacific Ocean and South China Sea that generate substantial rainfall through out the 


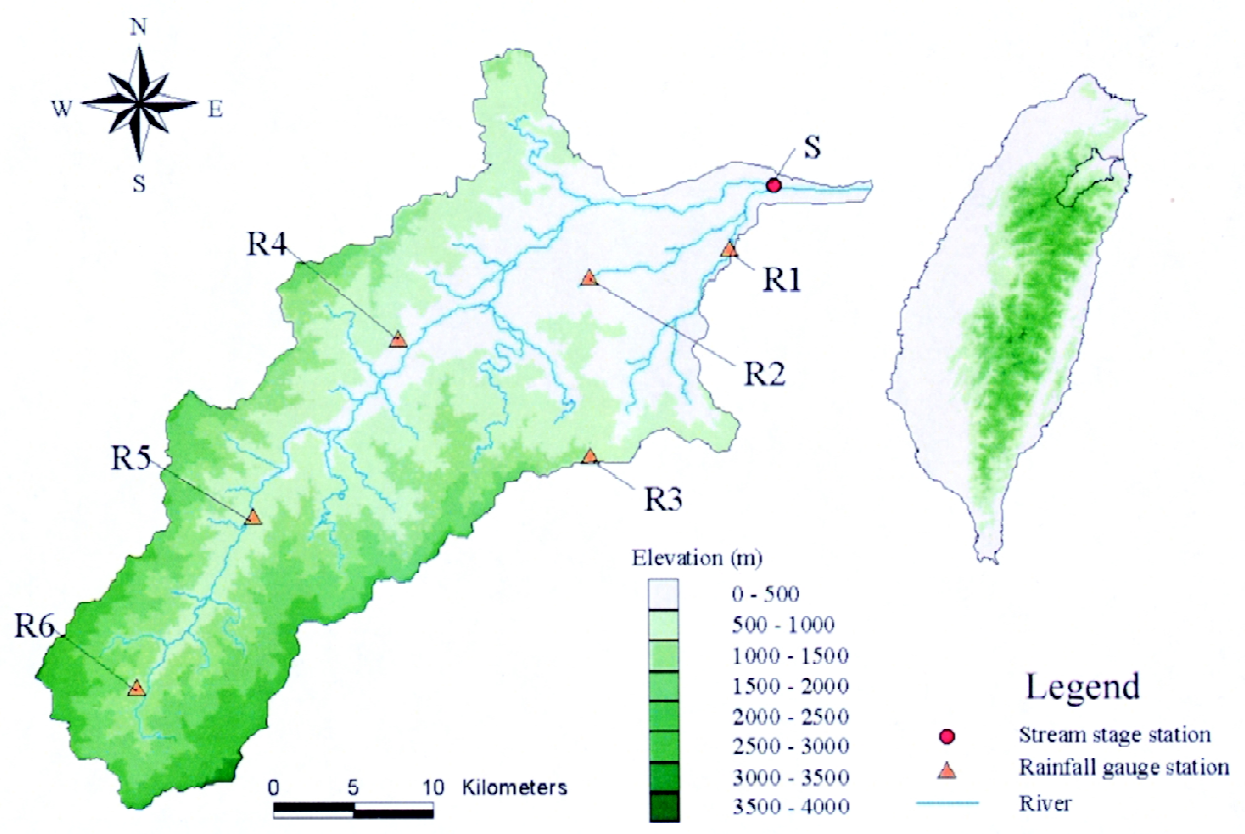

Fig. 1. Digital elevation map of Lanyan River Basin and Taiwan (shows the north-south-orientated Central Mountain Range in upright). R1 to R6 and $\mathrm{S}$ indicates the locations of six rainfall gauge stations and one stage station, respectively.

island (Chen and Chen 2003). Therefore, the expectation is that the seasonal rainfall pattern of the Lanyan River Basin is dominated by the winter monsoon during the dry season and by typhoons in the wet season. The influence of summer monsoon may be mitigated due to the location of the basin and the presence of the Central Mountain Range.

A total of six rainfall gauge stations (R1-R6) and a downstream stage station (S) providing observed stream discharges (Fig. 1) are used for analysis in this study. Table 1 shows the wet-season, dry-season, and annual rainfall depths $(\mathrm{mm})$ of each gauge station. The mean annual rainfall ranges from $2573 \mathrm{~mm}$ (R5) to $5625 \mathrm{~mm}$ (R3). This shows great spatial rainfall variability over the basin. Wet season rainfalls account for more than $60 \%$ of annual rainfall for all stations. At gauge station R4 the wet season rainfall reaches as high as $73 \%$ of annual rainfalls. The maximum daily discharge was $1940 \mathrm{~m}^{3} \mathrm{~s}^{-1}$, and the minimum daily discharge was as low as $3.7 \mathrm{~m}^{3} \mathrm{~s}^{-1}$.

\section{METHODOLOGY}

Irrespective of the methods used for areal rainfall estimation, a general mathematical representation of the average rainfall, $\mathrm{P}$, estimated over a basin can be given as, 


$$
P=\sum_{i=1}^{n} w_{i} p_{i},
$$

where $\mathrm{n}$ is the number of gauges (grids), $p_{i}$ and $w_{i}$ are the observed (estimated) rainfall and the associated weighting factor at the i-th gauge (grid), respectively. The summation of all weighting factors should be equal to unity. For example, $w_{i}$ is computed as the $\mathrm{i}$-th fractional area ratio, $\mathrm{A}_{\mathrm{i}} / \mathrm{A}$, where $\mathrm{A}_{\mathrm{i}}$ is the polygon area associated with the $\mathrm{i}$-th gauge and $\mathrm{A}$ is the area of the entire basin if the Thiessen polygon is applied for estimation. In the more general case of the optimal interpolation (e.g., kriging) using estimated grid rainfall, $\mathrm{A}_{\mathrm{i}}$ is the grid size and the weighting factor will be the same for all grids when a uniform grid size is considered.

In this study, gauge weighting factors, $w_{i}$, for estimating seasonal basin rainfall is determined through hydrological routing guided by tabu search. Brief descriptions of the hydrological model, tabu search strategy, and the integrated systematic procedures are introduced in the following subsections.

\subsection{Hydrological Model}

The flow routing module of a physics-based basin-scale hydrologic model, GWLF (General Watershed Loading Function; Haith et al. 1992; Haith and Shoemaker 1987), originally devel-

Table 1. Wet-season, dry-season, and annual rainfalls ( $\mathrm{mm})$ in the Lanyan River Basin and the seasonal rainfall percentages with respect to the annual amount are shown in brackets.

\begin{tabular}{|c|c|c|c|}
\hline Stations & $\begin{array}{c}\text { Wet Season } \\
\text { (May- October) }\end{array}$ & $\begin{array}{c}\text { Dry Season } \\
\text { (November - April) }\end{array}$ & Annual \\
\hline R1 & $1908(61 \%)$ & $1233(39 \%)$ & 3141 \\
\hline R2 & $2229(68 \%)$ & $1069(32 \%)$ & 3298 \\
\hline R3 & $3632(65 \%)$ & $1993(35 \%)$ & 5625 \\
\hline R4 & $2571(73 \%)$ & $935(27 \%)$ & 3506 \\
\hline R5 & $1962(76 \%)$ & $611(24 \%)$ & 2573 \\
\hline R6 & $1558(66 \%)$ & $799(34 \%)$ & 2357 \\
\hline
\end{tabular}


oped for calculating nonpoint sources in streams was applied to compute the river discharge. Figure 2 shows the schematic diagram of the GWLF flow module. The meteorological forcings are precipitation and evapotranspiration. Several important land hydrological processes including surface runoff; moisture contents in unsaturated zone, shallow, and deep saturated zones; percolation; deep seepage; and groundwater discharge are considered. Daily water balances are computed for unsaturated and shallow saturated zones as the equations given in Fig. 2. Infiltration to the unsaturated and shallow saturated zones equals the excess, if any, of rainfall less runoff and evapotranspiration. Percolation occurs when unsaturated zone water exceeds field capacity.

The monthly discharge is estimated as the summation of surface runoff $(\mathrm{Q})$ and groundwater discharge $(G)$. Surface runoff is estimated with the SCS curve number approach (Soil Conservation Service 1986) with considerations for 5-day antecedent soil moisture, crop growing season, landuse practices, and soil types. Infiltration into the unsaturated zone and shallow saturated zones is computed as the residual of given precipitation less runoff and evapotranspiration. Groundwater discharge is estimated with a recession factor to the mois-

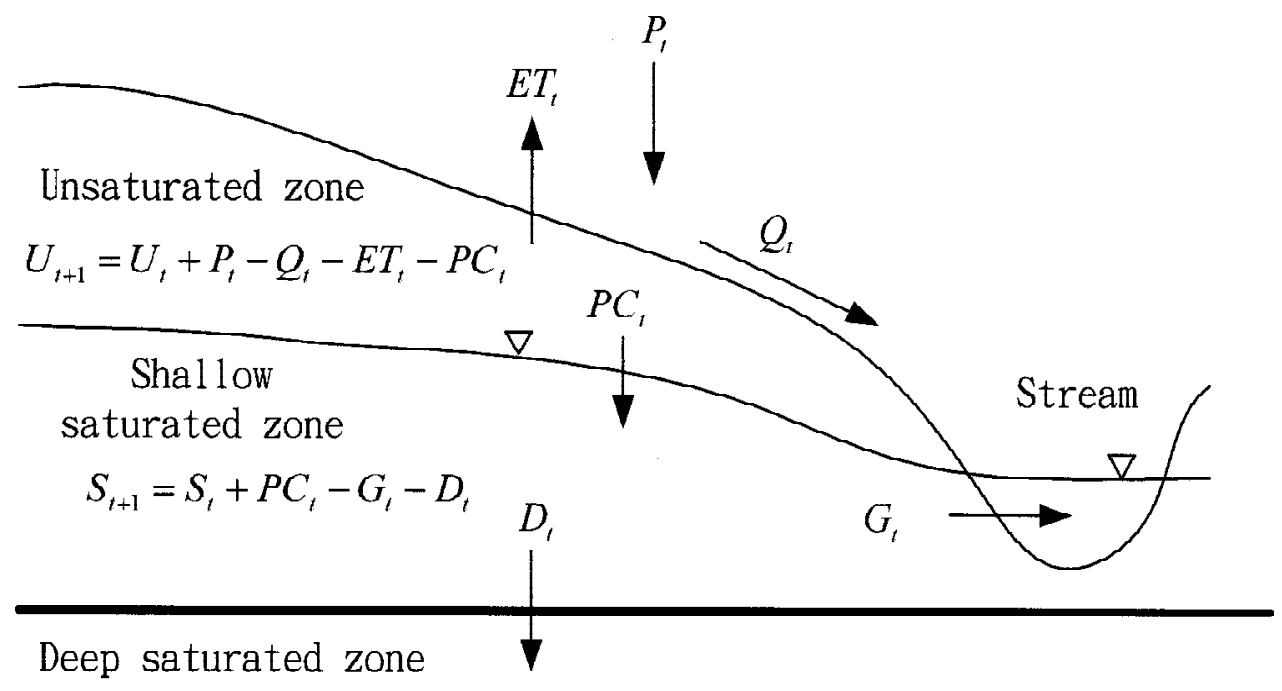

Fig. 2. Schematic diagram of the GWLF flow module, where $\mathrm{P}=$ precipitation, $\mathrm{ET}=$ evapotranspiration, $\mathrm{Q}=$ surface runoff, $\mathrm{G}=$ groundwater discharge, $\mathrm{U}=$ moisture content of the unsaturated zone, $\mathrm{S}=$ moisture content of the saturated zone, $\mathrm{PC}=$ percolation from the unsaturated zone into the shallow saturated zone, $\mathrm{D}=$ deep seepage form the shallow saturated zone into the deep saturated zone, and the subscript " $t$ " denotes the $t$-th day. The units of variables are " $\mathrm{cm}$ " representing the basin average depth at daily base. (modified after Haith et al. 1992) 
ture content of the shallow saturated zone. Actual evapotranspiration is calculated with available soil moisture and a correction factor, accounting for different crop types and growing seasons, to the potential evapotranspiration computed by daily temperature, saturated water vapor pressure, and daylight hours. More details of the modeling procedures and selection of parameters can be found in Haith et al. (1992).

\subsection{Tabu Search}

Tabu search (TS) is a powerful searching algorithm suitable for solving highly nonlinear problems. The main components of TS include: (1) Initial solution, (2) Neighborhood and movement, (3) Tabu list, (4) Aspiration criteria, and (5) Stopping criteria. The functionality of each component is briefly introduced as the following.

\section{(1) Initial Solution}

Theoretically different initial solutions may lead to different local optimal solutions in a highly nonlinear problem. The beauty of TS is the initial solution can be randomly selected and through the optimization process embedded in TS to reduce the deviation of the optimums due to such improper selection of initial guesses. The key relies on the implementation of the subsequent components.

\section{(2) Neighborhood and Movement}

The essential idea of TS optimization is to move from one solution to the best solution, which is not prohibited by tabu list, among its neighboring solution domain. If the newly found optimal solution is better than any previously explored optimal solutions recorded in the tabu list, the list will be updated with this solution. Although any new solution could be worse than the current best result, TS keeps moving toward the best neighbored solution until the given stop criterion is met to avoid being trapped by a local optimum. It is noted that different delineations of a solution neighborhood may significantly affect search efficiency as a large neighborhood requires more searching time and less movements, and vice versa.

\section{(3) Tabu List}

Better solutions of recent iterations are recorded in the Tabu list serving as a strategic constraint for not moving back to the formerly searched solutions. The length of the list should not be too short, otherwise there is a risk of the search entering cycling trap. However if the list is too long the search process may become inefficient. Glover (1990) suggested the magic number 7 could be the first guess.

\section{(4) Aspiration Criteria}

The role of aspiration criteria in TS is to provide an exception from the constraint of the tabu list. When only part of the decision variable information is recorded in the tabu list, a true better solution among those in the current solution neighborhood may be ignored. This misjudgment can be resolved by including an aspiration criteria or recording all decision variable information in the tabu list.

\section{(5) Stopping Criteria}


Stopping criteria serve as a restriction for not to proceed further searching when the potential optimal solution is reached. It can be given as: (1) a required optimal solution (2) a maximum iteration number or (3) a number of successive iterations where solutions are not improved. There is no predominant practice for the best selection of this type of criteria.

\subsection{Procedures}

Figure 3 shows the flow chart of our approach combining the GWLF model and TS for determining gauge weighting factors. Input data including daily precipitation, temperature, and daylight hours are applied to drive hydrological routings. Since the output of GWLF stream flow is described as the basin average runoff depth on a monthly scale, the observed and estimated monthly discharges are used to compute the Root Mean Square Error

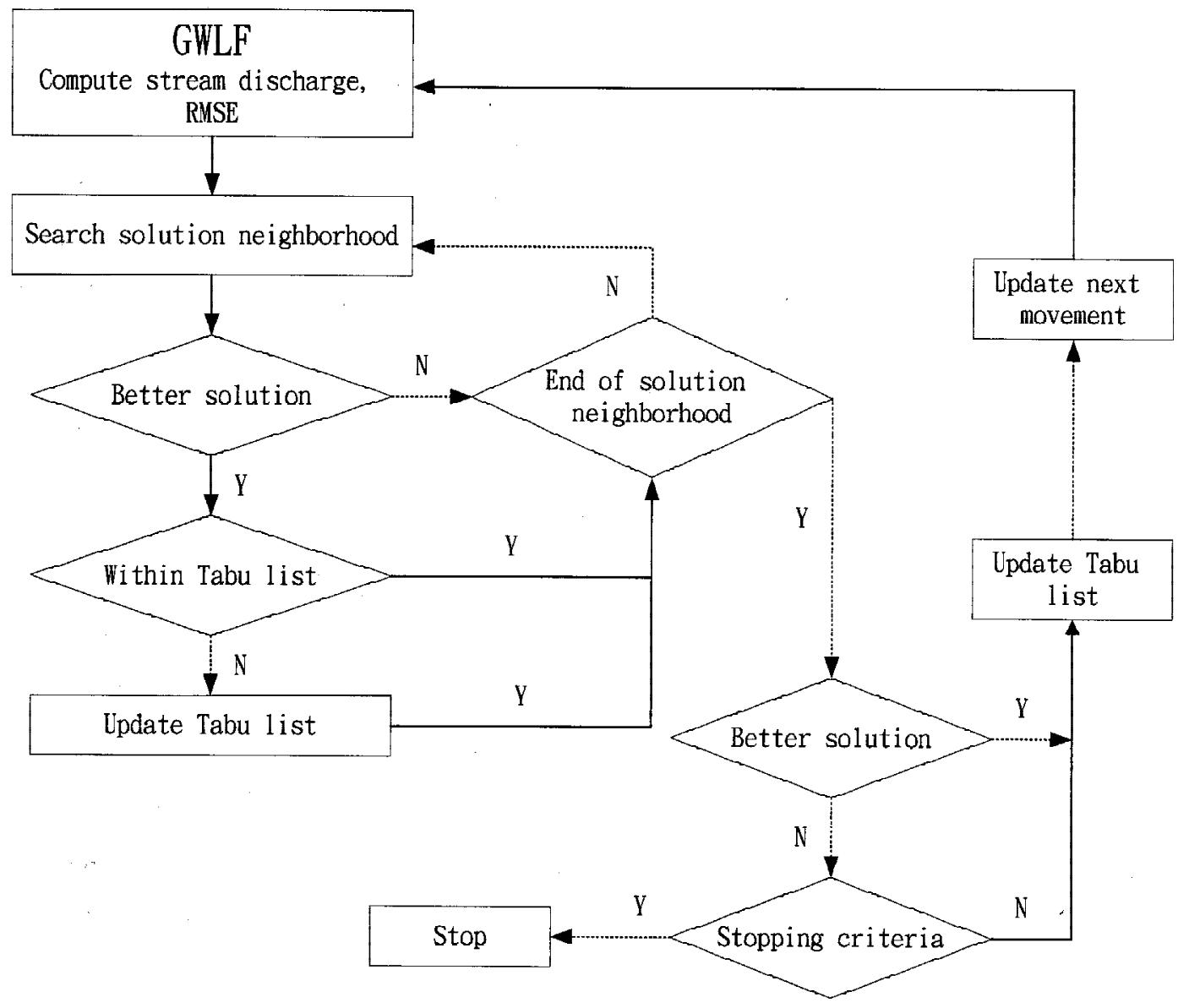

Fig. 3. Tabu search procedure for determining gauge weighting factors. 
$\left\{\right.$ RMSE $=\left[\Sigma\left(S_{i}-O_{i}\right)^{2} / n\right]^{1 / 2}$ where $S_{i}$ and $O_{i}$ are the simulated and observed runoff depths at the $i$-th month, respectively, and $\mathrm{n}$ is the number of months $\}$ as the objective function.

In this study the solution neighborhood of gauge weightings is defined as

$$
\begin{cases}w_{i} \pm m & i \in(1,2,3, \perp, n) \\ w_{j} \mathrm{~m} \frac{m}{n-1} & j \in(1,2,3, \perp, n), j \neq i\end{cases}
$$

where $w_{i}$ is the weighting factor of the $i$-th gauge station, $n$ is the number of gauges which is 6 in this study, and $m$ is the step correction amount, set a value of 0.05 . Hence in this scheme once a gauge is randomly selected to increase (decrease) its assigned weighting factor by 0.05 , however, in order to satisfy the constraint that weighting factors of all gauges in the study is to be unity the remaining 5 gauges' weighting factors decrease (increase) by 0.01 . Therefore the solution neighborhood contains a total of 12 possible combinations because there are six gauges each with two possible trials, increase or decrease. The GWLF model is then applied to route the stream discharge of each combination and compute its RMSE. The solution with the smallest RMSE, the better solution neighborhood, is recorded into the tabu list and the worst one in the current list is removed.

The next movement will proceed to the better solution neighborhood if it is not prohibited in the tabu list, otherwise the iteration function is followed and the next movement still proceeds to the better solution neighborhood. If the better solution neighborhood is superior to the current global best solution, it will be recorded as the best solution and the iteration number will be reset to zero. A maximum movement number of 100 is used as the stopping criterion to end further searching. Since all decision variables, weightings of the six gauges, are included in the tabu list, no aspiration criteria is needed in our approach.

Owing to data availability and to retain input rainfall consistency, daily rainfall depths and discharges of each station from 1973 - 1980 and 1982 - 1989 are collected for calibration and verification, respectively. The initialization of GWLF was achieved by using a data length of one year, namely 1973 and 1982 in this study. The conventional approaches of Thiessen polygon and arithmetic average were also applied to run GWLF as comparison references. In order to minimize the influence of initial guess in the TS and to study the possible effect of different initial solutions on searched results, both conventional approaches are taken as the initial weightings for performing tabu search.

\section{RESULTS AND DISCUSSIONS}

Initially, both wet- and dry-season rainfalls are examined with the approach proposed in this study. Consequently, annual rainfall, representing the combined effect of wet and dry seasonal forcings, is also investigated using the same systematic approach. Results of TS1 (Tabu Search 1) and TS2 (Tabu Search 2) are produced by using Thiessen and arithmetic weightings as the initial guesses, respectively, for searches in the following presentations. 


\subsection{Wet-season Rainfall}

Table 2 lists the comparisons of gauge weighting factors and the RMSEs of estimated monthly discharges by different approaches for wet-season rainfall of 1973 - 1980 as the calibration period and 1982 - 1989 as the validation period. Both TS1 and TS2 present similar results for gauge weightings and effectively reduce estimated discharge errors. The discharge RMSEs of the validation period demonstrate the successful implementation of the gauge weightings determined at the calibration period.

Table 2. Gauge-weighting factors and the RMSEs of estimated monthly discharges for wet-season rainfall with rainfall data of (a) 1973 - 1980 for calibration period and (b) 1982 - 1989 for validation period. Tabu Search 1 and Tabu Search 2 took the Thiessen weightings and the arithmetic averages, respectively, as the initial guesses for performing tabu search.

\begin{tabular}{|c|c|c|c|c|c|c|c|c|}
\hline Stations & \multicolumn{2}{|c|}{$\begin{array}{l}\text { Thiessen } \\
\text { weighting }\end{array}$} & \multicolumn{2}{|c|}{$\begin{array}{l}\text { Arithmetic } \\
\text { average }\end{array}$} & \multicolumn{2}{|c|}{ Tabu Search 1} & \multicolumn{2}{|c|}{ Tabu Search 2} \\
\hline $\bar{R} 1$ & \multicolumn{2}{|c|}{0.07} & \multicolumn{2}{|c|}{$1 / 6$} & \multicolumn{2}{|c|}{0.10} & \multicolumn{2}{|c|}{0.11} \\
\hline R2 & \multicolumn{2}{|c|}{0.20} & \multicolumn{2}{|c|}{$1 / 6$} & \multicolumn{2}{|c|}{0.05} & \multicolumn{2}{|c|}{0.05} \\
\hline R3 & \multicolumn{2}{|c|}{0.12} & \multicolumn{2}{|c|}{$1 / 6$} & \multicolumn{2}{|c|}{0.15} & \multicolumn{2}{|c|}{0.11} \\
\hline $\mathrm{R} 4$ & \multicolumn{2}{|c|}{0.21} & \multicolumn{2}{|c|}{$1 / 6$} & \multicolumn{2}{|c|}{0.12} & \multicolumn{2}{|c|}{0.16} \\
\hline R5 & \multicolumn{2}{|c|}{0.22} & \multicolumn{2}{|c|}{$1 / 6$} & \multicolumn{2}{|c|}{0.13} & \multicolumn{2}{|c|}{0.23} \\
\hline R6 & \multicolumn{2}{|c|}{0.18} & \multicolumn{2}{|c|}{$1 / 6$} & \multicolumn{2}{|c|}{0.45} & \multicolumn{2}{|c|}{0.34} \\
\hline \multirow{2}{*}{$\begin{array}{l}\text { RMSE } \\
(\mathrm{mm})\end{array}$} & (a) & (b) & (a) & (b) & (a) & (b) & (a) & (b) \\
\hline & 68.5 & 112.3 & 79.4 & 117.8 & 43.8 & 79.4 & 43.8 & 82.2 \\
\hline
\end{tabular}

Wet-season rainfall of the Lanyan River Basin is attributed mainly to the typhoons and partially to the southwesterly summer monsoon. The contribution from the summer monsoon might be diminished due to the existence of the Central Mountain Range and the location of the basin, northeastern Taiwan. Due to the basin orographic effect, the typhoon's cyclonic circulation may produce heavier rainfalls over mountainous areas than the plain area. As shown in Table 2, the R2 station has the lowest weighing factor, 0.05 , among six stations form both TS1 and TS2 results. The combined contribution of weightings from stations R3, R4, R5, and R6 are 0.85 (TS1) and 0.84 (TS2) as listed in Table 2. This presents the importance of orographic effect on wet-season rainfall in the Lanyan River Basin because these stations are randomly located at mid- and up-stream locals with mountainous topography (Fig. 1). It is 
noted that a high gauge weighting means the relative importance of observed rainfall at one station with respect to the regional rainfall pattern in the basin. Since typhoons often bring in rainfalls over the entire basin, invading from diverse directions, no significant windward or leeward effects are found in the searched gauge weightings.

The most significant discrepancies in the searched weighting factors are found at $\mathrm{R} 2$ and R6, one decreased and the other one increased with respect to those given by both conventional approaches. As shown in Fig. 1, station R2 is located at the low land area of the basin downstream whilst station R6 is located upstream in the basin. The lower weighting of R2 can be explained by its location downstream in the low lands of the basin, where the associated rainfall is less representative in this mountainous watershed. One interesting result is that station R6 has the lowest observed wet-season rainfall (Table 1) but the highest weighting factors (Table 2). This can be explained by further examining the estimated stream hydrographs as discussed in the next paragraph.

Figure 4 shows the comparisons of estimated discharges for wet seasons with different combinations of gauge weighting factors at the calibration period. The estimated discharges with both conventional approaches are overestimated during high flow months, mainly from Aug. to Oct., in some years (e.g., 1974, 1975, and 1976). The estimated discharges by our algorithms significantly reduced the errors associated with those high flow months. Similar results were also found during the validation period as shown in Fig. 5. Since the objective function of our approach is the RMSE of stream discharges, our integrated hydrological routing and TS produce an increased R6 weighting and a lowered R2 weighting. In other words, high wet-season rainfall observed at some stations might be the results of fast moving cyclones (e.g., typhoon circulations). Here the areal coverage of high-intensity rainfall is relatively smaller than the weighting given by conventional approaches. Therefore, the gauge weighting factors determined by this approach for wet season rainfall can only quantify the overall orographic effect in the Lanyan River Basin rather than project relative significance among mountainous station gauges.

\subsection{Dry-season Rainfall}

Table 3 lists the comparisons of gauge weighting factors and the RMSEs of estimated monthly discharges for dry-season rainfall at calibration and validation periods. The superiority on estimated stream discharges by both TS1 and TS2 were also found as the reduced RMSEs.

Dry-season rainfall of the Lanyan River Basin is mainly attributed to the northeasterly winter monsoon. The weighing factors of stations R4, R5, and R6 determined by our approach are higher than those of other stations. This result explains the relative importance of the orographic effect on dry-season rainfall. Although station R3 has the highest observed dry season rainfall among six stations (Table 1), the R3 weighting is lower than that of R4, R5, or R6 as listed in Table 3. This might be explained by the location of station R3 near the basin's southeast boundary (Fig. 1). Here the rainfall pattern at R3 might be less representative than those patterns of R4 to R6 located along the main stream.

The most significant finding is that station R5 has the largest gauge-weighting factor among all six stations. The reason being that station R5 is located right on the windward side 

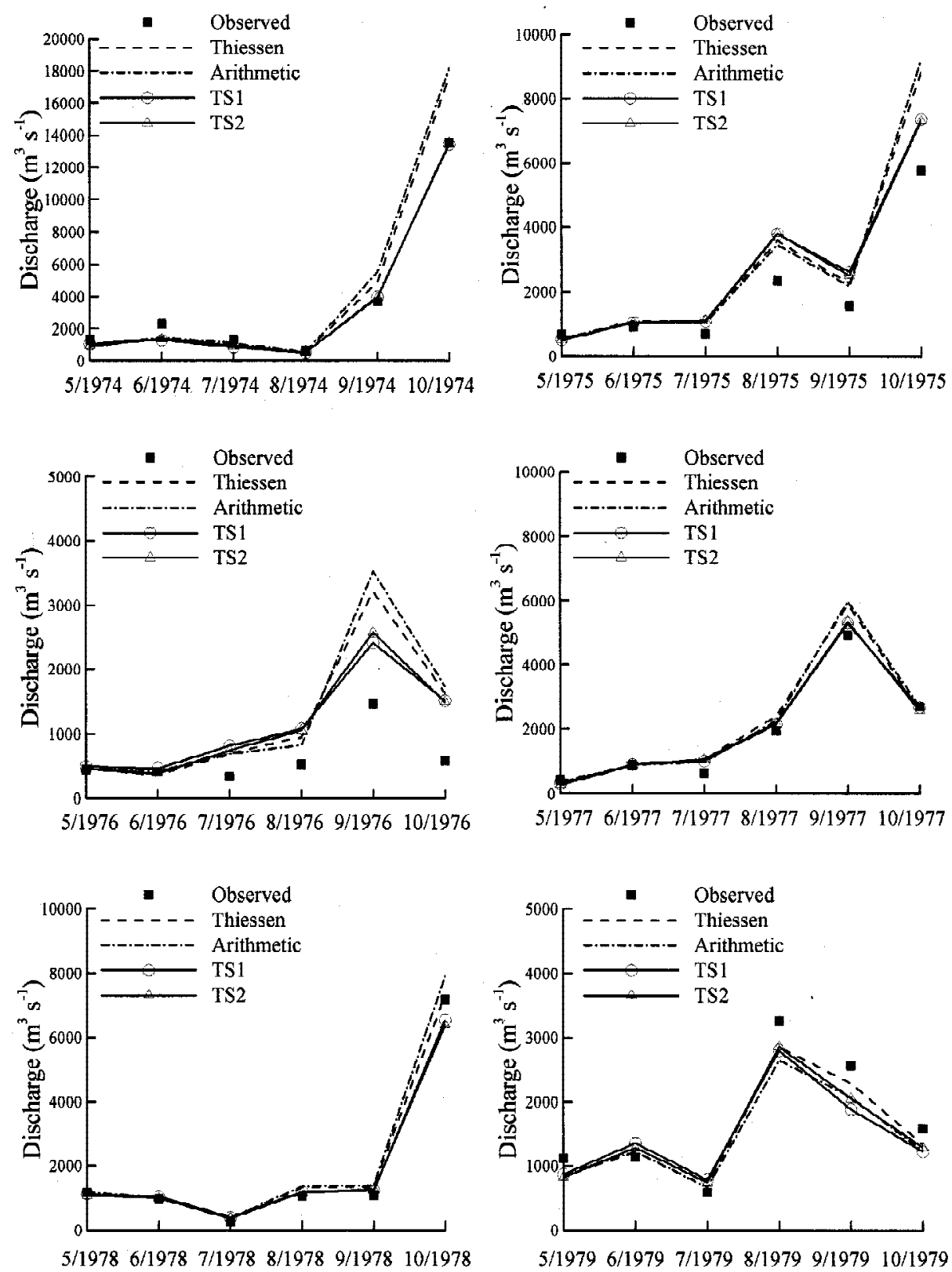

Fig. 4. Comparisons of estimated monthly discharges of wet seasons with different gauge weighting factors for calibrations. (Note: TS1 and TS2 took the Thiessen weightings and the arithmetic averages, respectively, as the initial guesses for performing tabu search.) 

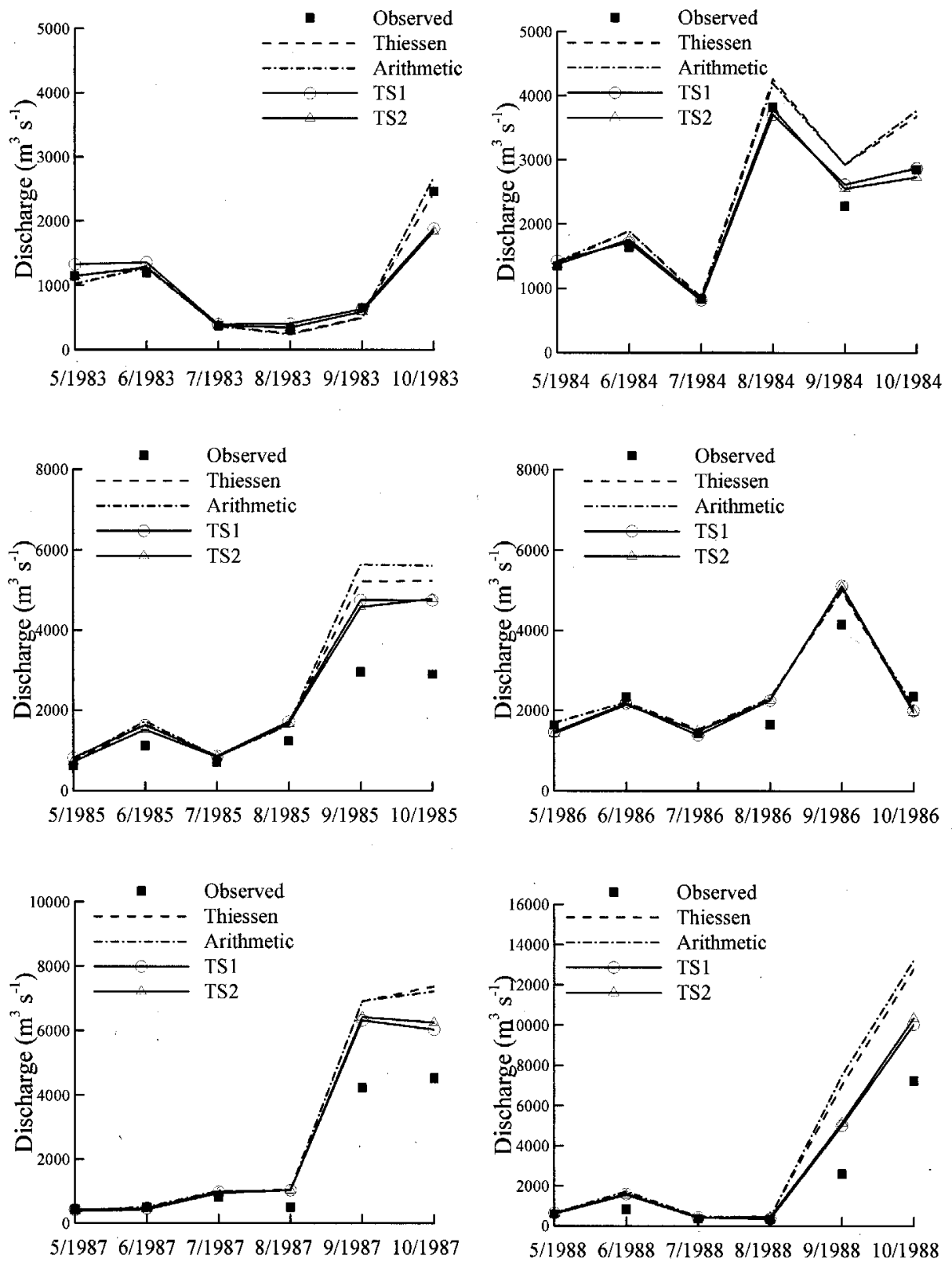

Fig. 5. Comparisons of estimated monthly discharges of wet seasons with different gauge-weighting factors for validations. 
Table 3. Gauge-weighting factors and the RMSEs of estimated monthly discharges for dry-season rainfall with rainfall data of (a) 1973 - 1980 for calibration period and (b) 1982 - 1989 for validation period.

\begin{tabular}{|c|c|c|c|c|c|c|c|c|}
\hline Stations & \multicolumn{2}{|c|}{$\begin{array}{l}\text { Thiessen } \\
\text { weighting }\end{array}$} & \multicolumn{2}{|c|}{$\begin{array}{l}\text { Arithmetic } \\
\text { average }\end{array}$} & \multicolumn{2}{|c|}{ Tabu Search 1} & \multicolumn{2}{|c|}{ Tabu Search 2} \\
\hline $\mathrm{R} 1$ & \multicolumn{2}{|c|}{0.07} & \multicolumn{2}{|c|}{$1 / 6$} & \multicolumn{2}{|c|}{0.01} & \multicolumn{2}{|c|}{0.02} \\
\hline R2 & \multicolumn{2}{|c|}{0.20} & \multicolumn{2}{|c|}{$1 / 6$} & \multicolumn{2}{|c|}{0.02} & \multicolumn{2}{|c|}{0.02} \\
\hline R3 & \multicolumn{2}{|c|}{0.12} & \multicolumn{2}{|c|}{$1 / 6$} & \multicolumn{2}{|c|}{0.06} & \multicolumn{2}{|c|}{0.08} \\
\hline $\mathrm{R} 4$ & \multicolumn{2}{|c|}{0.21} & \multicolumn{2}{|c|}{$1 / 6$} & \multicolumn{2}{|c|}{0.27} & \multicolumn{2}{|c|}{0.25} \\
\hline R5 & \multicolumn{2}{|c|}{0.22} & \multicolumn{2}{|c|}{$1 / 6$} & \multicolumn{2}{|c|}{0.52} & \multicolumn{2}{|c|}{0.56} \\
\hline R6 & \multicolumn{2}{|c|}{0.18} & \multicolumn{2}{|c|}{$1 / 6$} & \multicolumn{2}{|c|}{0.12} & \multicolumn{2}{|c|}{0.07} \\
\hline RMSE & (a) & (b) & (a) & (b) & (a) & (b) & (a) & (b) \\
\hline$(\mathrm{mm})$ & 49.3 & 52.0 & 65.6 & 65.6 & 30.1 & 30.1 & 32.8 & 32.8 \\
\hline
\end{tabular}

with respect to the northeasterly winter monsoon, while stations R4 and R6 are located on the leeward sides. As shown in Fig. 1, the areal coverage of the windward side corresponding to the winter monsoon roughly accounts for more than half the Lanyan River Basin. This might further explain why station R5 has the largest weighting of 0.52 (TS1) and 0.56 (TS2) as listed in Table 3. Results from the dry-season rainfall run demonstrate our approach successfully locates relatively important stations when the regional rainfall pattern shows significant windward and leeward orographic effects. Therefore the weighing factors of stations in the downstream lowlands (e.g., R1 and R2) are determined to be smaller than for the others.

Figures 6 and 7 depict the comparisons of estimated discharges for dry seasons with different gauge weighting factors for calibration and validation, respectively. The estimated discharges with gauge weightings determined by our approach are superior to those of the conventional approaches. These typically overestimate stream flows during both high and low flow months. For dry-season rainfall, the proposed algorithm is capable of identifying relatively important stations with high gauge weightings reflecting regional rainfall patterns dominated by orographic and significant windward effects associated with the northeasterly winter monsoon.

\subsection{Annual Rainfall}

In addition to the studied seasonal rainfalls, we applied our approach to annual rainfall in order to examine the effect of distinctive wet- and dry-season-rainfall patterns on estimating the annual gauge weightings. Table 4 shows the comparisons of gauge weighting factors and 


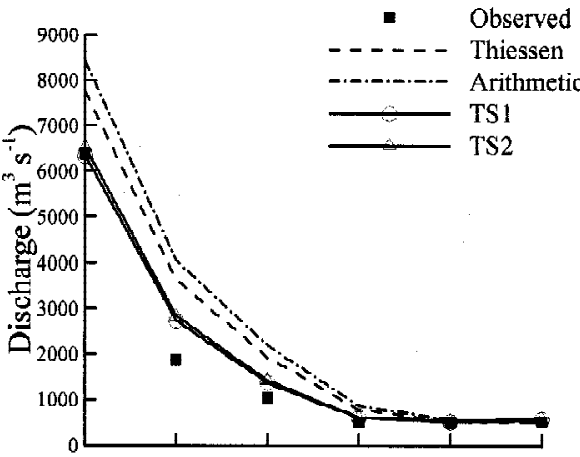

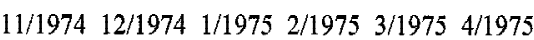

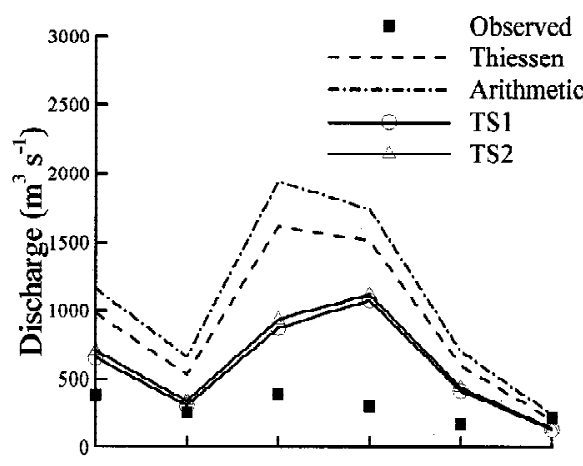

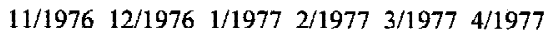

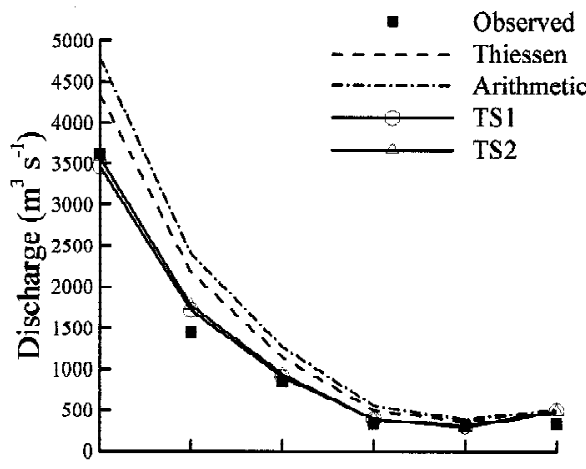

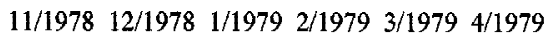
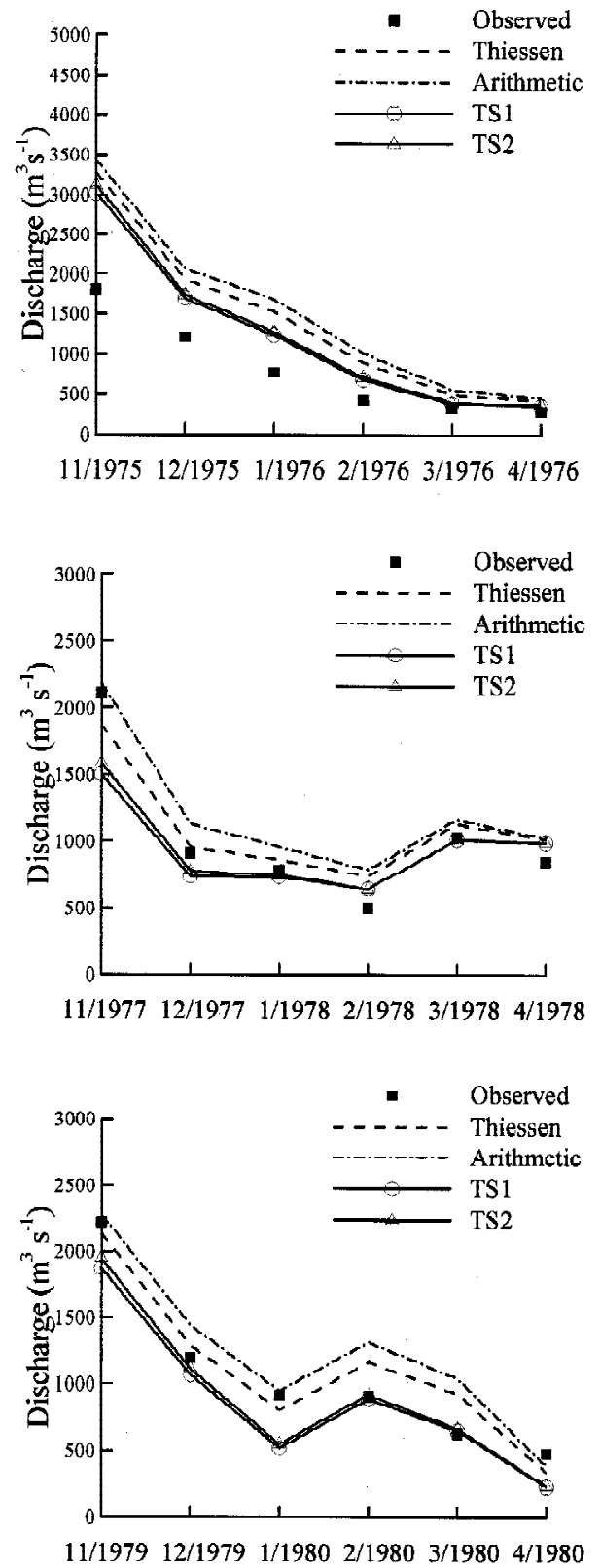

Fig. 6. Comparisons of estimated monthly discharges of dry seasons with different gauge-weighting factors for calibrations. 

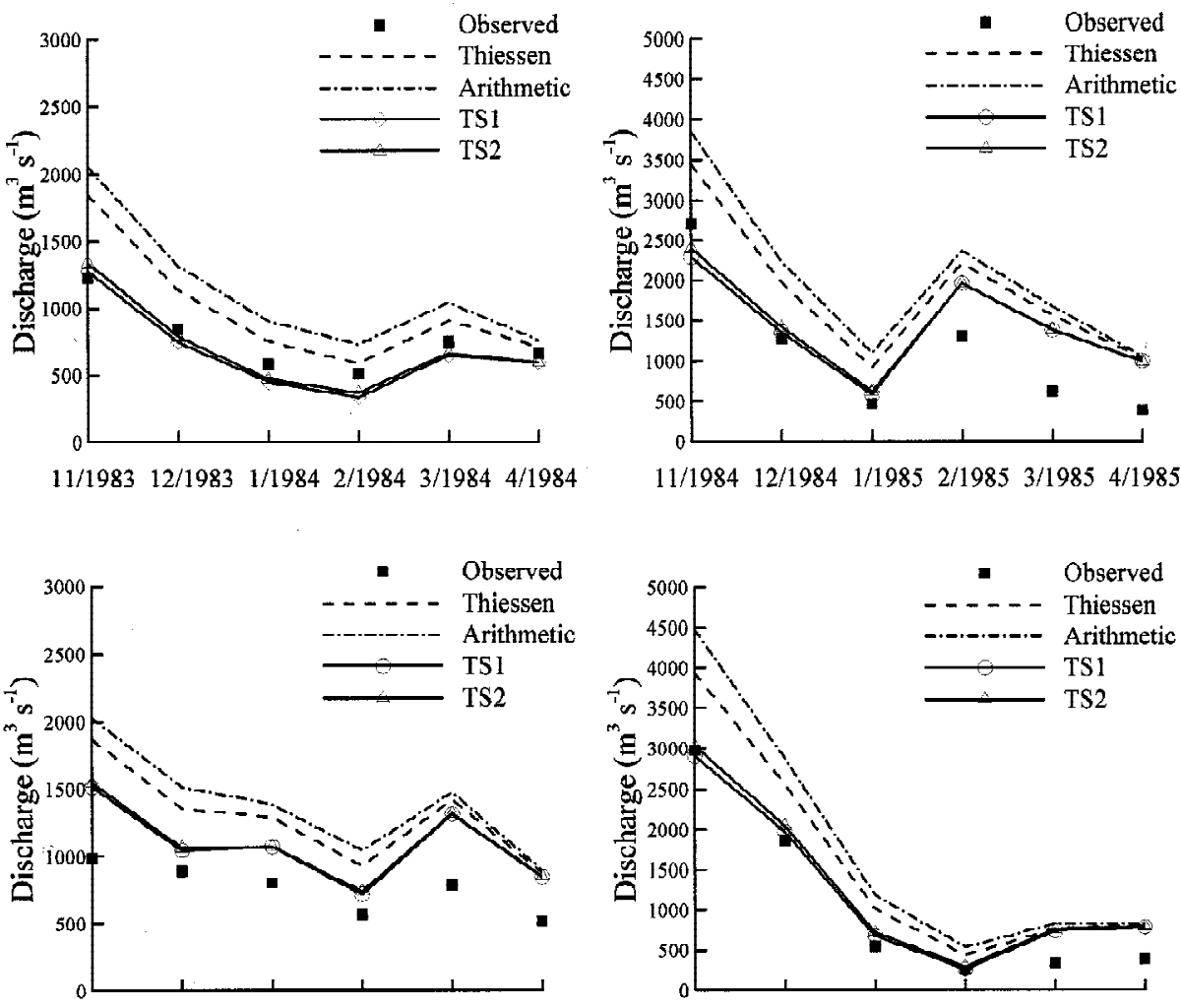

$\begin{array}{lllllll}11 / 1985 & 12 / 1985 \quad 1 / 1986 \quad 2 / 1986 & 3 / 1986 \quad 4 / 1986\end{array}$

$\begin{array}{llllll}11 / 1986 & 12 / 1986 \quad 1 / 1987 \quad 2 / 1987 & 3 / 1987 & 4 / 1987\end{array}$
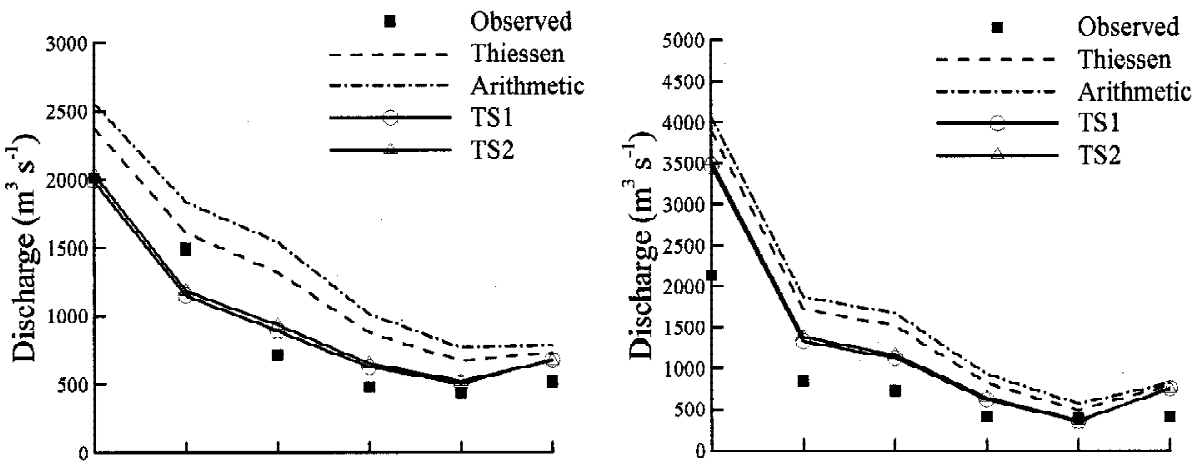

$\begin{array}{lllllll}11 / 1987 \quad 12 / 1987 & 1 / 1988 \quad 2 / 1988 \quad 3 / 1988 & 4 / 1988\end{array}$

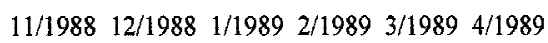

Fig. 7. Comparisons of estimated monthly discharges of dry seasons with different gauge-weighting factors for validations. 
the RMSEs of estimated monthly discharges at calibration and validation periods. Again the weightings searched by both TS1 and TS2 are superior to the two conventional approaches. Gauge weightings of stations R4, R5, and R6 have higher values than those of the other stations. This shows the importance of orographic effect in the estimation of annual basin rainfall. Also, the fact that station R3 has a relatively small weighting is associated with its location near the basin boundary.

Figure 8 depicts comparisons of estimated monthly discharges with different gauge-weighting factors for calibration and validation, respectively. The estimated discharges with our algorithm are superior to those of the conventional approaches, especially for some high flow months. It is noted that the gauge weighting factors determined for long-term continuous rainfalls can only identify the orographic effect (e.g., R4 to R6) and reject the less correlated station (e.g., R3).

\subsection{Comparison of Results}

By comparing the RMSEs of estimated discharges listed in Tables 2, 3, and 4, it is noted that the dry season case presents with the best and most stable skill. This demonstrates the importance of persistent rainfall patterns in estimating gauge weighting factors and hydrological routings. For both the wet-season and annual cases, although the RMSEs of estimated discharges deteriorated during the validation period, the results of our approach are still superior to those of the conventional approaches. This might be attributed to high spatial rainfall variability during the wet season in the Lanyan River Basin.

Table 4. Gauge-weighting factors and the RMSEs of estimated monthly discharges for annual rainfall with rainfall data of (a) 1973 - 1980 for calibration period and (b) 1982-1989 for validation period.

\begin{tabular}{|c|c|c|c|c|c|c|c|c|}
\hline Stations & \multicolumn{2}{|c|}{$\begin{array}{l}\text { Thiessen } \\
\text { weighting }\end{array}$} & \multicolumn{2}{|c|}{$\begin{array}{c}\text { Arithmetic } \\
\text { average }\end{array}$} & \multicolumn{2}{|c|}{ Tabu Search 1} & \multicolumn{2}{|c|}{ Tabu Search 2} \\
\hline R1 & \multicolumn{2}{|c|}{0.07} & \multicolumn{2}{|c|}{$1 / 6$} & \multicolumn{2}{|c|}{0.04} & \multicolumn{2}{|c|}{0.01} \\
\hline R2 & \multicolumn{2}{|c|}{0.20} & \multicolumn{2}{|c|}{$1 / 6$} & \multicolumn{2}{|c|}{0.05} & \multicolumn{2}{|c|}{0.07} \\
\hline R3 & \multicolumn{2}{|c|}{0.12} & \multicolumn{2}{|c|}{$1 / 6$} & \multicolumn{2}{|c|}{0.03} & \multicolumn{2}{|c|}{0.01} \\
\hline R4 & \multicolumn{2}{|c|}{0.21} & \multicolumn{2}{|c|}{$1 / 6$} & \multicolumn{2}{|c|}{0.30} & \multicolumn{2}{|c|}{0.36} \\
\hline R5 & \multicolumn{2}{|c|}{0.22} & \multicolumn{2}{|c|}{$1 / 6$} & \multicolumn{2}{|c|}{0.25} & \multicolumn{2}{|c|}{0.19} \\
\hline R6 & \multicolumn{2}{|c|}{0.18} & \multicolumn{2}{|c|}{$1 / 6$} & \multicolumn{2}{|c|}{0.33} & \multicolumn{2}{|c|}{0.36} \\
\hline RMSE & (a) & (b) & (a) & (b) & (a) & (b) & (a) & (b) \\
\hline$(\mathrm{mm})$ & 71.2 & 106.8 & 82.2 & 115.0 & 41.1 & 79.4 & 41.1 & 82.2 \\
\hline
\end{tabular}


Table 5 shows the comparisons of wet-season, dry-season, and annual rainfalls estimated with different gauge weighting factors. In the case of wet-season basin rainfall, the total depths evaluated with our approaches are $10 \%$ less than those by the Thiessen weighting and the arithmetic average. For dry-season basin rainfall, more than a $20 \%$ reduction is achieved with our approach. As a result, annual basin rainfall estimated with this integrated hydrological routing and TS algorithm is more than $10 \%$ less than conventional simple approaches. This is attributed primarily to the reduction in dry-season rainfall estimates.

Comparing the seasonal rainfall percentages with respect to the total annual amounts for different gauge weightings (see numbers shown in brackets of Table 5), both TS1 and TS2
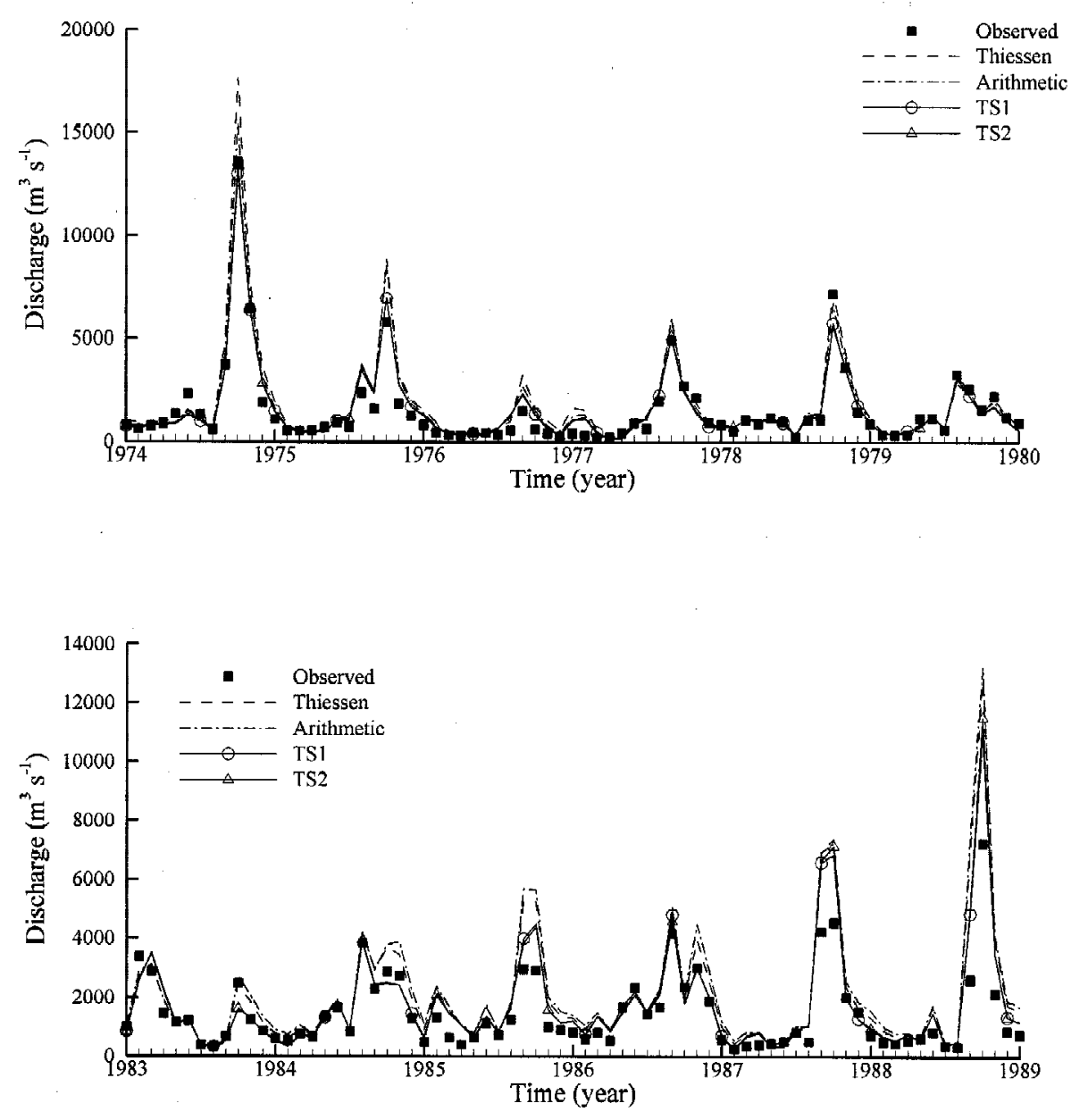

Fig. 8. Comparisons of estimated monthly discharges with different gauge-weighting factors determined for annual rainfall for calibration (top) and validation (down). 
Table 5. Comparisons of wet-season, and dry-season, and annual rainfalls with different gauge weighting factors, numbers in brackets are the rainfall percentages of wet and dry seasons with respect to the annual amounts.

\begin{tabular}{|c|c|c|c|c|}
\hline $\begin{array}{c}\text { Rainfall } \\
(\mathrm{mm})\end{array}$ & $\begin{array}{c}\text { Thiessen } \\
\text { Weighting }\end{array}$ & $\begin{array}{c}\text { Arithmetic } \\
\text { average }\end{array}$ & Tabu search 1 & Tabu search 2 \\
\hline Wet season & $2267(69 \%)$ & $2310(68 \%)$ & $2111(72 \%)$ & $2088(72 \%)$ \\
\hline Dry season & $1014(31 \%)$ & $1107(32 \%)$ & $821(28 \%)$ & $830(28 \%)$ \\
\hline Annual & 3281 & 3417 & 2932 & 2918 \\
\hline
\end{tabular}

results show a consistent partition of increasing the wet season percentage and lowing the dry season percentage. The consistent partition of seasonal rainfall percentages demonstrates the superiority of TS to reach optimum solutions with poor initial guess, e.g., the arithmetic weighting in this study. The changes in seasonal rainfall percentages are mainly attributed to the greater reduction in dry-season rainfall than wet-season rainfall.

\section{CONCLUSIONS}

In this paper we present an approach combining hydrological routings and Tabu Search to determine gauge weighting factors in estimating seasonal basin rainfalls. The basic approach is to assign values to gauge-weighting factors that better represent the relative importance of each station in the basin-rainfall pattern. In other words, the gauge weighting of a station is the ratio of the fractional area, which has a similar rainfall pattern associated with that particular station, to the entire basin area. It is noted that gauge stations with high rainfalls do not necessarily have large weightings because this may be only a localized effect or the result of poor records.

Our results show the mountain stations typically have higher weightings than those located downstream in the basin. This demonstrates that orographic effect is important in estimating seasonal basin rainfall in the Lanyan River Basin. When the seasonal rainfall is dominated by a persistent frontal system, such as the northeasterly winter monsoon in this study, our approach is capable of identifying the windward effect in estimating basin rainfall as the largest weighting factor determined for a particular windward station (R5). However when the frontal system is insignificant, like during wet-season rainfall, which is dominated by cyclonic rainfalls, only orographic effect can be identified by our approach.

From the results shown by TS1and TS2 (Tables 2, 3, and 4), it is clear that TS is a powerful searching algorithm for nonlinear problems and capable of diminishing the errors induced by poor initial guesses. We also compared the convergent histories of both TSs on estimating gauge-weighting factors for seasonal and annual rainfalls during the calibration period(Fig. 9). 

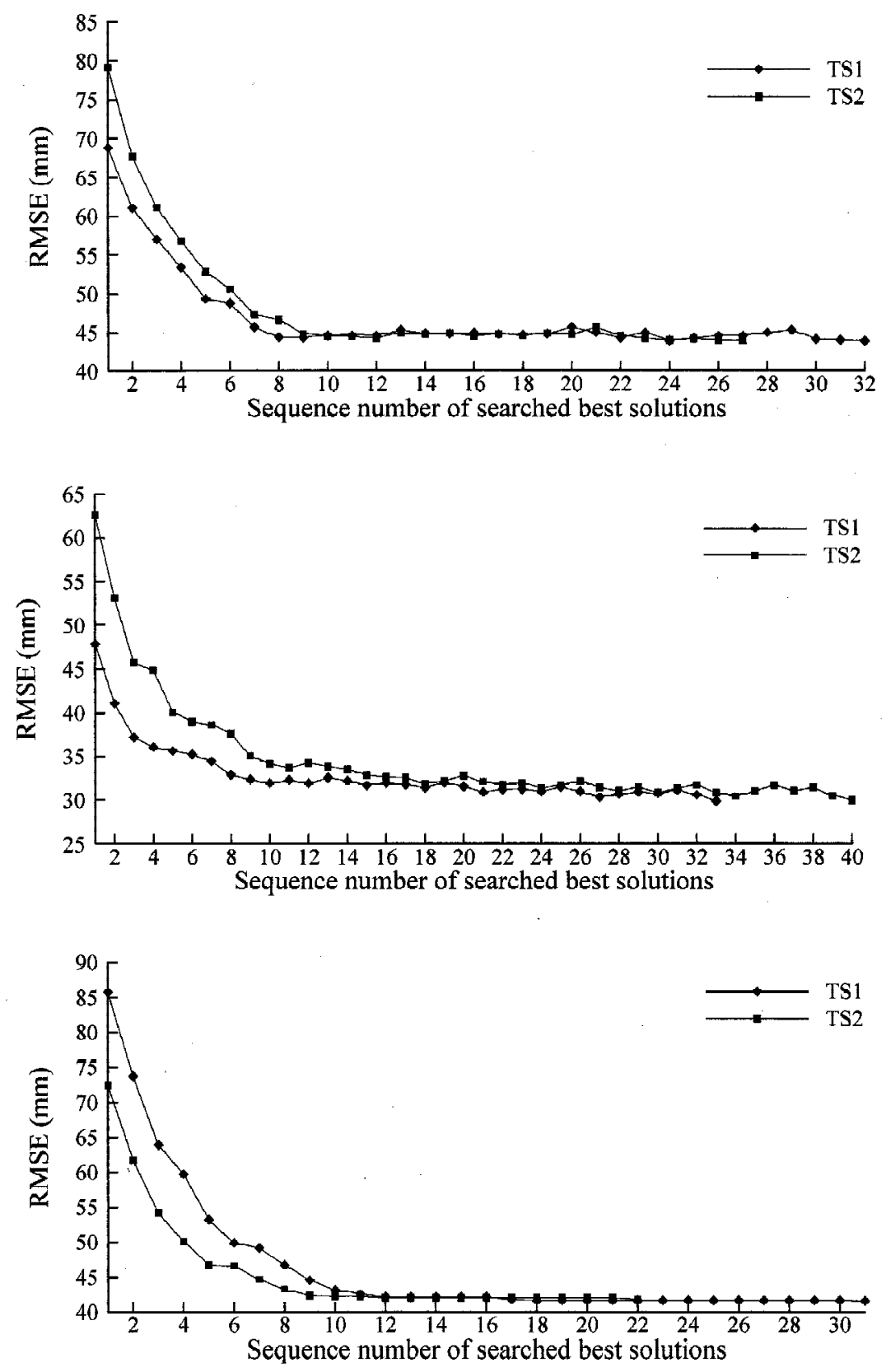

Fig. 9. Convergent histories of TS1 and TS2 on searching gauge-weightings for wet season (top), dry season (middle), and annual (bottom) rainfalls at calibration period. 
Normally after the 10-th best solution was found, the RMSEs were significantly reduced in this study and consequent improvement in RMSEs became slow. No more than 40 best solutions were needed to reach the optimum gauge weighting combinations. Therefore we can conclude that the stopping criterion of 100 iterations without updating the best solution applied in this study is too restrictive. To make the search algorithm more efficient, an alternative criterion, such as consecutive insignificant RMSE improvement, ought to be used future study.

Since there are six gauges involved in this study, the entire solution domain should contain $100^{6}$ trials because the weighting of each station can be changed from 0.0 to 1.0 with a step change of 0.01 given each station 100 possibilities. Using the proposed approach, only an average of less than 1600 trials was searched to reach optimum solutions. This demonstrates that the combination of hydrological routings and TS is effective and efficient in determining weighting factors for estimating seasonal-basin rainfall.

It is noted that the weighting factors determined in this study are only associated with their corresponding seasonal rainfall characteristics and not suitable for estimating the basin rainfall of any individual event. As concluded by Syed et al. (2003), basin runoffs are highly affected by directional movement of storms and the position of a storm's core in the analysis of event-based spatial rainfall characteristics. Future applications of our approach could include the incorporation of the classification of general weather patterns to more precisely identify important gauge weightings. For event rainfall, a physically-based distributed hydrological model utilizing a grid-based spatial rainfall distribution ought to be applied. Here a zonation approach might present the best alternative to effectively reduce the degree of freedom induced by the requirement of massive grid-based rainfall data.

Acknowledgements This study is partially supported by the National Science Council of Taiwan under contract NSC-91(92)-2621-Z-008-009 with the National Central University. Valuable hydrometeorological data are provided by the Central Weather Bureau and Water Resources Agency of Taiwan. The authors are grateful for their supports.

\section{REFERENCES}

Bacchi, B., and N. T. Kottegoda, 1995: Identification and calibration of spatial correlation patterns of rainfall. J. Hydrol., 165, 311-348.

Chaubey, I., C. T. Haan, S. Grunwald, J. M. Salisbury, 1999: Uncertainty in the model parameters due to spatial variability of rainfall. J. Hydrol., 220, 48-61.

Chen, C. S., and Y. L. Chen, 2003: The rainfall characteristics of Taiwan. Mon. Wea. Rev., 131, 1323-1341.

Dingman, S. L., 2002: Physical Hydrology. $2^{\text {nd }}$ ed., Prentice Hall, NJ.

Einfalt, T., G. Johann, and A. Pfister, 1998: On the spatial validity of heavy point rainfall measurements. Water Sci. Technol., 37, 21-28.

Glover, F., 1986: Future paths for integer programming and links to artificial intelligence. Comp. Oper. Res., 13, 533-549. 
Glover, F., 1990: Tabu search: part II. ORSA J. Comp., 2, 4-32.

Goovaerts, P., 2000: Geostatistical approaches for incorporating elevation into the spatial interpolation of rainfall. J. Hydrol., 228, 113-129.

Haith, D. A., R. Mandel, and R. S. Wu, 1992: GWLF: General Watershed Loading Function, Version 2.0., User's Manual, Cornell University.

Haith, D. A., and L. L. Shoemaker, 1987: Generalized watershed loading functions for stream flow nutrients. Water Resour. Bull., 23, 471-478.

McCuen, R. H., 1998: Hydrologic Analysis and Design. $2^{\text {nd }}$ ed., Prentice Hall, NJ.

Pardo-Igúzquiza, E., 1998: Optimal selection of number and location of rainfall gauges for areal rainfall estimation using geostatisticals and simulated annealing. J. Hydrology, 210, 206-220.

Singh, V. P., 1997: Effect of spatial and temporal variability in rainfall and watershed characteristics on stream flow hydrograph. Hydrol. Proc., 11, 1649-1669.

Soil Conservation Service, 1986: Urban hydrology for small watersheds. Technical Release No. 55, U.S. Department of Agriculture.

Syed K. H., D. C. Goodrich, D. E. Myers, and S. Sorooshian, 2003: Spatial characteristics of thunderstorm rainfall fields and their relation to runoff. J. Hydrol., 271, 1-21.

Tabios, G. Q., and J. D. Salas, 1985: A comparative analysis of techniques of spatial interpolation of precipitation. Water Resour. Res., 21, 365-380.

Thiessen, A. H., 1911: Precipitation for large areas. Mon. Wea. Rev., 39, 1082-1084.

Tung, C. P., and C. A. Chou, 2002: Application of Tabu search to ground water parameter zonation. J. Am. Water Resour. Assoc., 38, 1115-1125.

Viessman, W. Jr., and G. L. Lewis, 2003: Introduction to Hydrology, $5^{\text {th }}$ ed., Prentice Hall.

Yoo, Chulsang, and E. Ha, 2002: Basin average rainfall and its sampling error.Water Resour. Res., 38, 1259-1265.

Zheng, C., and P. Wang, 1996: Parameter structure identification using Tabu search and simulated annealing. Adv. Water Resour., 19, 215-224.

Zheng, C., and P. Wang, 1999: An integrated global and local optimazation approach for remediation system design. Water Resour. Res., 35, 137-148. 